\title{
PHYSICAL ANALYSIS OF CROSS-WEDGE ROLLING PROCESS OF A STEPPED SHAFT
}

\author{
Łukasz Wójcik' , Zbigniew Pater ${ }^{1}$ \\ 1 Lublin University of Technology, Mechanical Engineering Faculty, Nadbystrzycka 36, 20-618 Lublin, Poland, \\ e-mail: I.wojcik@pollub.pl
}

Received: 2017.07.18

Accepted: 2017.11.01

Published: 2017.12.05

\begin{abstract}
The paper presents experimental- model research results on the process of cross-wedge rolling of an axially-symmetrical element (stepped shaft). During research plastic mass on the basis of waxes in black and white colour was used. The aim of this experimental research was to determine the best option of forming in terms of values obtained and the course of forces. Physical examination was carried out using specialist machines, i.e. model and a laboratory cross-wedge rolling mill. Experimental analysis was carried out using billets with the temperature of $15^{\circ} \mathrm{C}$, whereas the actual process was carried out for billet from $\mathrm{C} 45$ carbon steel of temperature $1150^{\circ} \mathrm{C}$. The study compared the dimensions of the components obtained during rolling tests and forming forces obtained in the result of physical modeling with forces obtained during real tests.
\end{abstract}

Keywords: physical modeling, plasticine, cross-wedge rolling

\section{INTRODUCTION}

Metal forming industry continually tends to reduce production costs and design time of new manufacturing processes, yet, it also aims at higher product quality. Enterprises that optimize their production processes in this direction, increase profits without losing quality of manufactured goods. Due to the characteristic for this type of production constraints that occur in an industrial environment, experimental studies are often impossible.

The introduction of a new product into production without prior experimental analysis, in the event of an error appearance, generates very high costs for the company. Therefore, forges are looking for new methods to improve the course of the design of metal forming processes technologies and, at the same time, which would reduce costly trials on the material in real industrial conditions. The application of these techniques al- lows to perform research on the process of metal forming in laboratory conditions at a room temperature, using tools made of materials which are cheaper and easier for processing $[7,17,18]$.

Techniques making the process of constructing tools and technologies of metal forming easier which are currently used in the industry include two methods, i.e. numerical modeling (mathematical) and physical modeling. Numerical modeling is based on solving differential equations, using the discretization of the test object at a finite number of elements. In the case of mathematical modeling, five methods can be distinguished: finite differences, finite element, boundary element, finite volume, and methods without mesh. The main advantages of numerical techniques are the possibilities of obtaining results for complex shapes and the easiness of carrying out software simulation $[2,5]$. The disadvantage of numerical research is uncertainty of the simulation results that may be caused by false boundary assump- 
tions adopted during computer analysis. This uncertainty should be compared with the test result in industrial conditions. Despite its flaws, this method is most popular among the research and development units and manufacturing enterprises, both in Poland and abroad.

Tests conducted using physical modeling techniques simplify the analytical analysis of studied technological processes. This solution allows for replacing the actual material by a material model. Physical modeling technique is based on four main pillars of similarity [4]: the similarity of curves of the material model flow to the actual material, the similarity of friction conditions, the similarity of the tools shape, and the similarity of the kinematics of the analyzed process. Proper planning of experimental research requires assuming appropriate material modeling of a real material. A semi-finished product model should have a low strength properties and low melting temperature. Selecting material according to the above conditions allows for the usage of less expensive tools, usually made of rubber, plastics or resins.

Model materials used for experimental analysis of technological processes can be divided into two main groups, which are metallic and non-metallic products. The materials belonging to the group of non-metallic are cheap and easily undergo metal forming. Non-metallic materials include: waxes, elastomers, resins, celluloid and plasticine, while the group of metallic materials includes, among others, lead and tin.

During research on metal forming processes the most frequently used materials are lead and various types of plasticine, which is a mixture of clays, oils and waxes.

\section{ANALYSIS OF ISSUES}

Plasticine is a product that is highly plastic at room temperature, however, at a lower temperature it loses plasticity but it does not change its properties forever. Its advantage is the possibility of multiple usage and non-drying in the air, what is the most desirable feature characteristic of this type of material. Plasticine was repeatedly used in experimental research on metal forming technological processes $[8,13,20,21]$. As a result of literature analysis it was stated that this material as a semi-finished product was successfully used for physical modeling of numerous forging and extrusion processes. It was observed that there was a niche associated with physical modeling of forging rolling processes and cross- wedge rolling processes. In the past, however, the tests of processes modeling with the application of plasticine were considered. And so the problem of physical modeling of the rolling process in the planetary system of three rolls and rolling rings is described in the articles $[6,14,15]$. Modeling of rolling using screw rolls was taken by the team of N. R. Chitkara in 1975 [3], which conducted a physical analysis of the process of balls forming using plasticine as a material model. Therefore, it was considered appropriate to conduct a physical research of cross-wedge process, which in terms of the kinematics of material flow is similar to screw rolling.

Cross-wedge rolling is used for metal forming of axially symmetrical products that takes place with the application of tools in a form of wedges. These tools can be made in a form of a flat plate or an appropriately shaped cylinder. The schema of the cross-wedge rolling process course at the application of two flat wedges is shown in Fig.1. During the rolling of forgings by means of CWR method, disturbances may occur, such
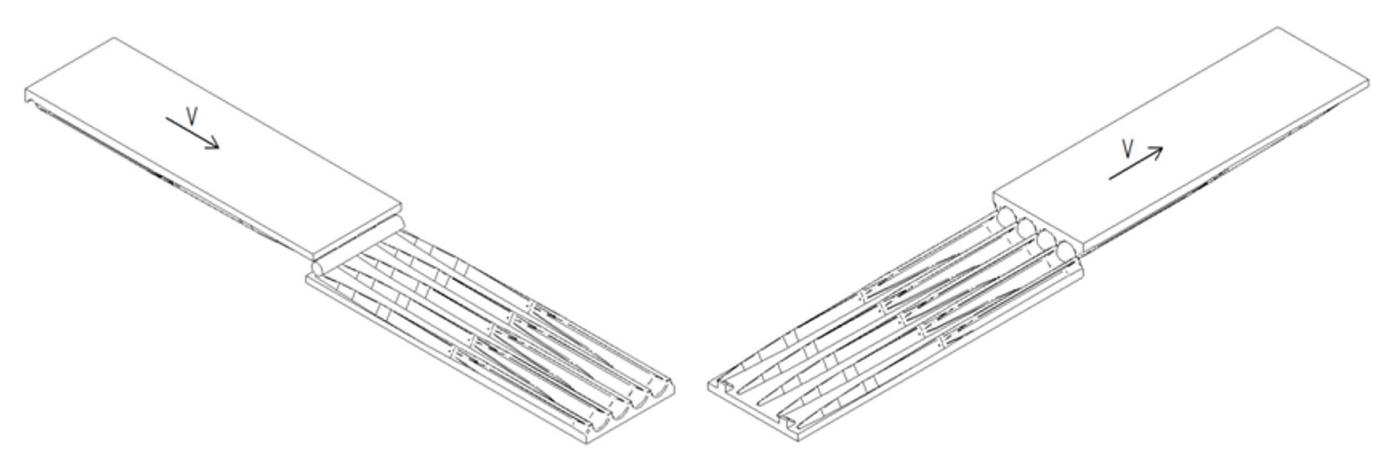

Fig. 1. Schema of the cross-wedge rolling process of balls 
as slipping between the product and tool, necking of the rolled forging and uncontrolled cracking of the formed forgings [11]. The research works of the cross-wedge rolling process have been realized at Lublin University of Technology for 25 years [10].

Plastometer studies of wax-based plasticine are sensitive to changes in temperature and strain rate. The drop in temperature and an increase in strain rate of the analyzed material resulted in a significant increase in yield stress. The plastic mass used for the tests carried out in the temperature range of $0,5,10,15$ and $20^{\circ} \mathrm{C}$ shows the highest yield stress for the lowest temperature at the highest speed, where they are equal to $\sigma_{\mathrm{pl}}=$ $0.67 \mathrm{MPa}$. The worked out flow curves show that the yield stresses initially increase, then decrease to a certain limit value. The diagram (Fig.2) presents comparison of flow curves for plasticine at temperature $15^{\circ} \mathrm{C}$. Plasticine on the basis of wax is elastic- plastic material which is characterized by varying value of Young's modulus (Tab. 1).

Material model (commercial plasticine) was described by two constitutive equations, equation (1) describes material of white colour; however, the second equation (2) describes yield stresses for plasticine of black colour.

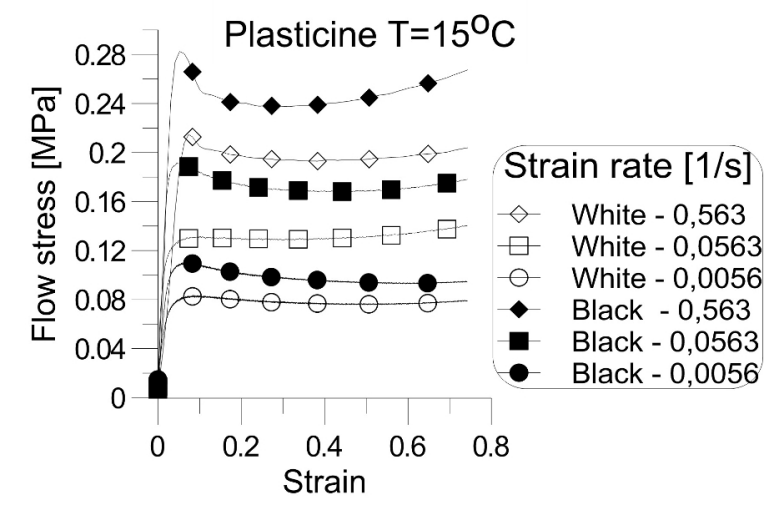

Fig.2 Plasticine flow curves

$$
\begin{gathered}
\sigma_{p}=0,48057 \cdot \varepsilon^{-0,03127} \cdot \exp (0,08705 \cdot \varepsilon) \\
\cdot \dot{\varepsilon}^{(0,245080,00262 T)} \cdot \exp (-0,03283 T) \\
\sigma_{p}=0,6817 \cdot \varepsilon^{-0,0711} \cdot \exp (0,07203 \cdot \varepsilon) \\
\cdot \dot{\varepsilon}^{(0,27010,003 T)} \cdot \exp (-0,07358 T)
\end{gathered}
$$

where: $\sigma_{p}-$ yield stress $[\mathrm{MPa}]$,

$$
\begin{aligned}
& \varepsilon-\text { strain }[-], \\
& \dot{\varepsilon}-\text { strain rate }\left[\mathrm{s}^{-1}\right], \\
& T-\text { forming temperature }\left[{ }^{\circ} \mathrm{C}\right] .
\end{aligned}
$$

Similarity coefficient between steel $\mathrm{C} 45$ at various temperatures and plastic mass at temperature $15^{\circ} \mathrm{C}$ was also determined. For this coefficient calculation of the dependency (3) was used. The calculated values are presented in Table 2.

$$
\lambda=\frac{\int_{0}^{1} \sigma_{\text {STEEL }} d \varepsilon}{\int_{0}^{1} \sigma_{\text {PLASTICINE }} d \varepsilon}
$$

\section{THE RESEARCH STAND}

For model research of the cross-wedge rolling process a research stand designed and manufactured in the Department of Computer Modelling and Metal Forming at Lublin University of Technology was used. Laboratory research stand reflects in a scale of 0.25 rolling mill located in the same department (Fig.3). This stand was built on the basis of a laboratory drawing machine shown in Fig.4.

The research stand is composed of three main groups: drawing machine with a controller, measuring system, module of model rolling mill equipped with wedge tools (Fig.4b).

Table 1. Comparison of Young module values for plasticine

\begin{tabular}{|c|c|c|c|c|c|}
\hline $\mathrm{E}[\mathrm{MPa}]$ & $\mathrm{T}=20^{\circ} \mathrm{C}$ & $\mathrm{T}=15^{\circ} \mathrm{C}$ & $\mathrm{T}=10^{\circ} \mathrm{C}$ & $\mathrm{T}=5^{\circ} \mathrm{C}$ & $\mathrm{T}=0^{\circ} \mathrm{C}$ \\
\hline White plasticine & 2.60 & 4.84 & 6.31 & 10.14 & 9.51 \\
\hline Black plasticine & 2.33 & 7.18 & 10.06 & 11.77 & 12.44 \\
\hline
\end{tabular}

Table 2. Similaritiy coefficients

\begin{tabular}{|c|c|c|c|c|c|}
\hline \multicolumn{2}{|c|}{$\lambda$} & \multicolumn{4}{c|}{ STEEL T $\left[{ }^{\circ} \mathrm{C}\right]$} \\
\cline { 3 - 6 } & 1150 & 1100 & 1050 & 1000 \\
\hline \multirow{2}{*}{$\begin{array}{c}\text { PLASTICINE } \\
\mathrm{T}=15^{\circ} \mathrm{C}\end{array}$} & BLACK & 266.15 & 317.09 & 377.8 & 450.16 \\
\cline { 2 - 6 } & WHITE & 330 & 393.9 & 469.3 & 559.23 \\
\hline
\end{tabular}




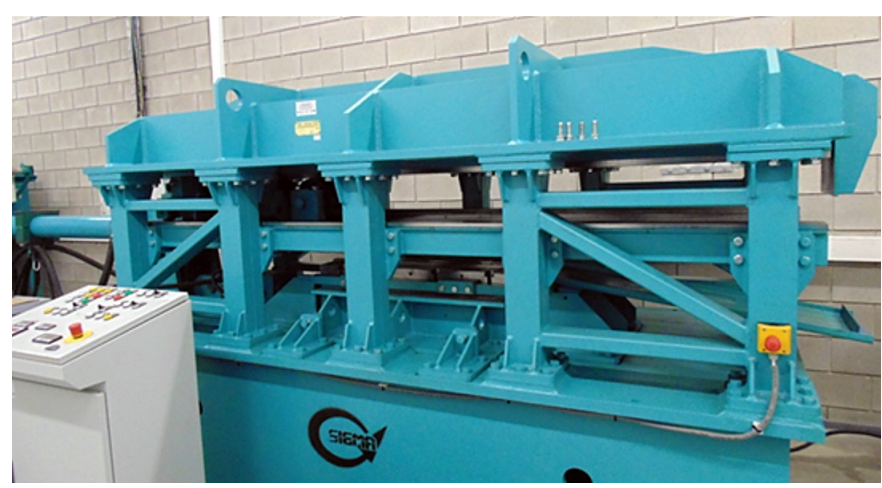

Fig. 3. Cross-wedge rolling mill
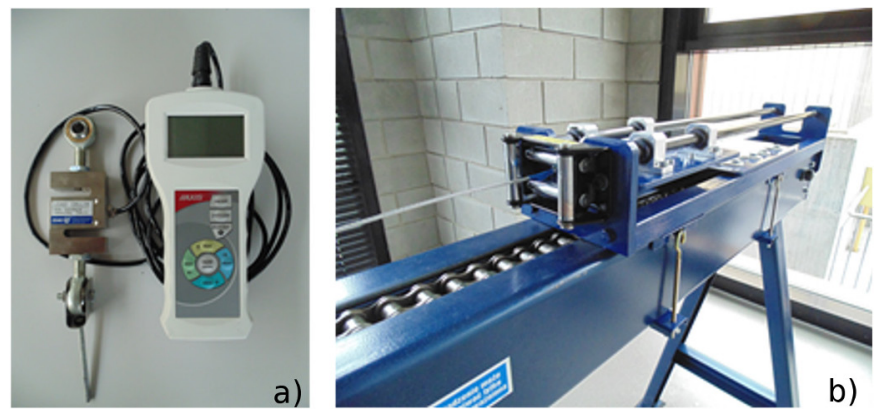

Fig. 4. Elements of research stand a) measuring system b) model cross-wedge rolling mill

Laboratory drawing machine has the possibility of linear speed regulation of tools within the range of 0 to $147 \mathrm{~mm} / \mathrm{s}$.

As the measurement system dynamometer AXIS FC1K was used, allowing for the measurement with very high speeds of up to 1000 measurements per second (Fig. 4a). The model of the sensor has a measuring range of forces to $1 \mathrm{kN}$ and a readable scale of $0.2 \mathrm{~N}$. The accuracy of the measuring system used is equal to $\pm 0.1 \%$ of span.

The construction of the rolling module allows for quick installation on the drawing machine. It consists of four main components: the frame with installed pulley slide allowing for gentle movement of the drive cable; the fixed lower plate with the fixed lower tool; the upper movable plate with mounted wedge and guiding devices allowing for horizontal movement of the tools.

The tools used for physical research were made using 3D printing technology FFF / FDM.
Printing technique used here is based on melting the plastic (in this case ABS) and laying it in thin layers $(\approx 0.25 \mathrm{~mm})$. For tools making the printer uPrint SE was used. The tools were made of two interconnected segments. They were made in a scale of 0.25 in relation to the actual tools used in the laboratory mill (Figure 5).

\section{THE EXPERIMENTAL TESTS OF FORGINGS FORMING}

For conducting tests of physical modeling of the cross-wedge process material model from the group of non-metallic materials-plasticine was used. During research, the plasticine on the waxbasis of two colours-white and black was applied. The product obtained in the rolling process was the forging of a shaft shown in Figure 6. In model
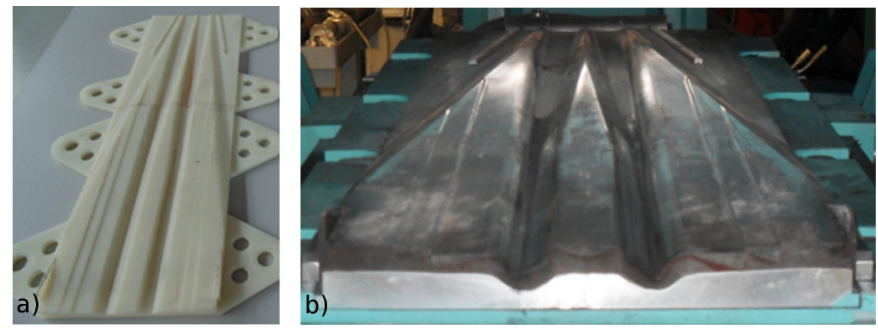

Fig. 5. Tools a) tools for model research b) tools for real research 
research a shaft of the same shape was rolled, yet in the scale of 1:4.

Before performing the research, the material model was properly prepared. From many different methods of preparation of preforms described in the literature $[1,9,12,16,19]$, a method was adopted in accordance with the following procedure. The first step of billet preparation was heating the plastic mass to the temperature of approximately $35^{\circ} \mathrm{C}$, such a chosen temperature allows for easier multiple manual forming of plasticine parts supplied by the manufacturer. This treatment is used to get rid of air bubbles that arose as a result of production. In the next stage, cylindrical bodies were prepared, from which in the next step rods of circular cross-section with a diameter of $12.5 \mathrm{~mm}$ and a length of $80 \mathrm{~mm}$ were squeezed. For the experiment needs, 6 of each color samples were prepared. The final stage of preparations for the research was cooling of the formed material to the temperature of $15^{\circ} \mathrm{C}$. The billet was kept in a laboratory refrigerator for 24 hours, such time allowed to achieve uniform temperature throughout the whole volume.

During the implementation of model tests force and duration of the sampling frequency of $100 \mathrm{~Hz}$ were registered. For each of the colors of the plastic mass were made 3 forgings of dimensions four times smaller than real forging. On the basis of the recorded force values, the diagram of changes of forging forming force was determined. The photographs (Figure 7) show the obtained shafts. The graph (Figure 8) shows the averaged courses of forces for both plasticines.

In order to compare the process modeled physically with the real process, steel forging in hot $\left(1150^{\circ} \mathrm{C}\right)$ was made of the shaft shown in Fig.9. As the material of forging was adopted carbon steel C45. During the real research parameters were recorded at a frequency of $1000 \mathrm{~Hz}$. The collected values of measurement were presented as a graph of the force in the road function (Figure 10).

After analyzing the course of forming forces and the values of the dimensions of the diameter and length of the particular steps of the shaft (Table 3) plasticine that most closely projected the real material was selected. It was observed that white plasticine has the most similar distribution of forming force in relation to the rolling of forging from steel. Plastic properties of white mass allowed for the most accurate representation of the shape of the steel forging.

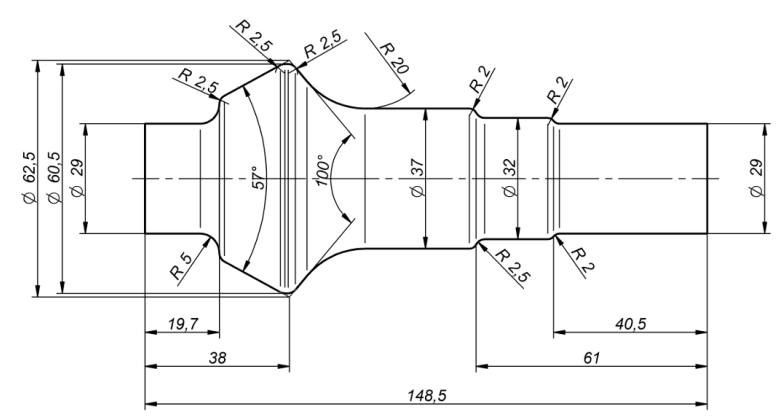

Fig. 6. Shape and nominal dimensions of the rolled forging

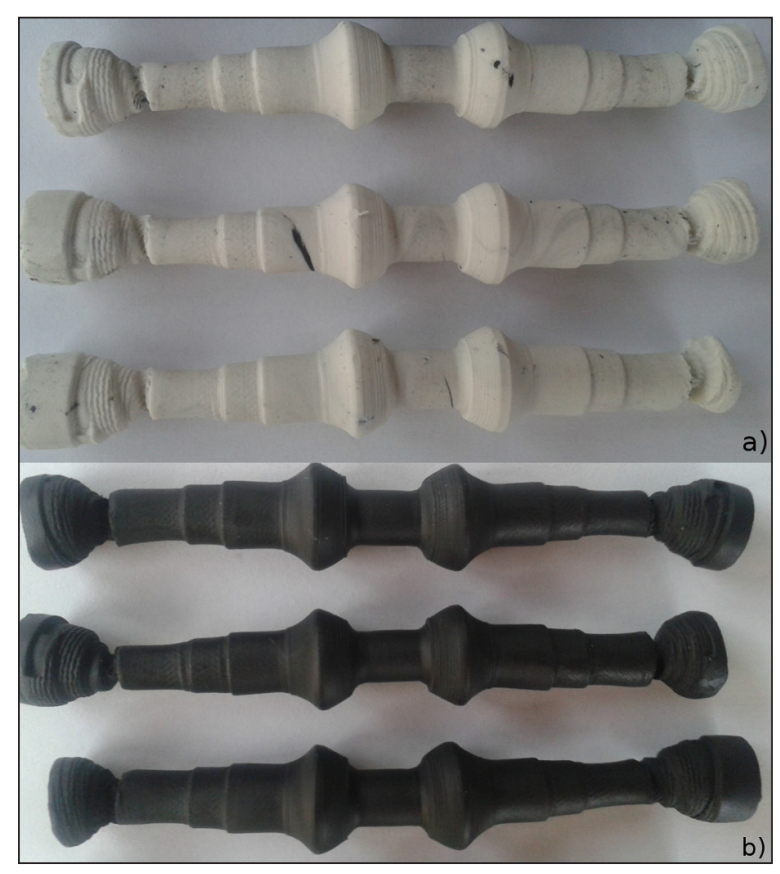

Fig. 7. Forgings obtained during physical modelling a) white plasticine b) black plasticine

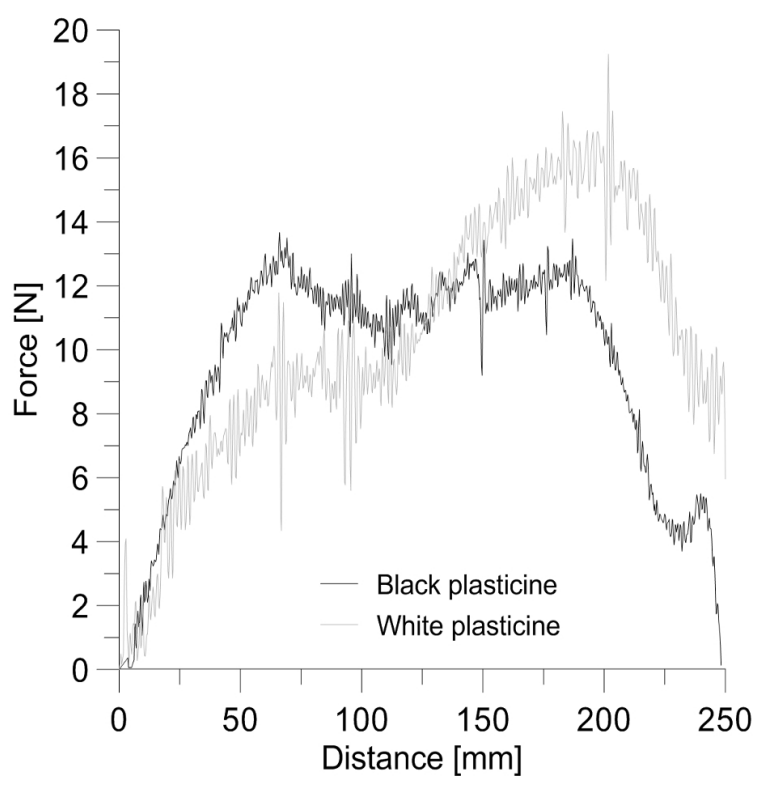

Fig. 8. Graph of force moving wedge during forming of plasticine shafts 


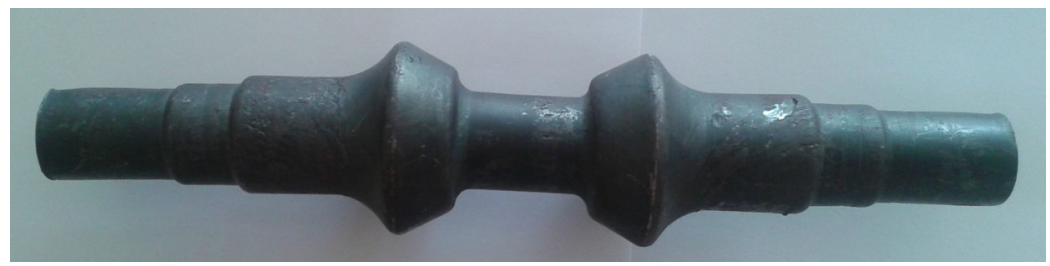

Fig. 9. Steel forming obtained in real cross-wedge rolling process

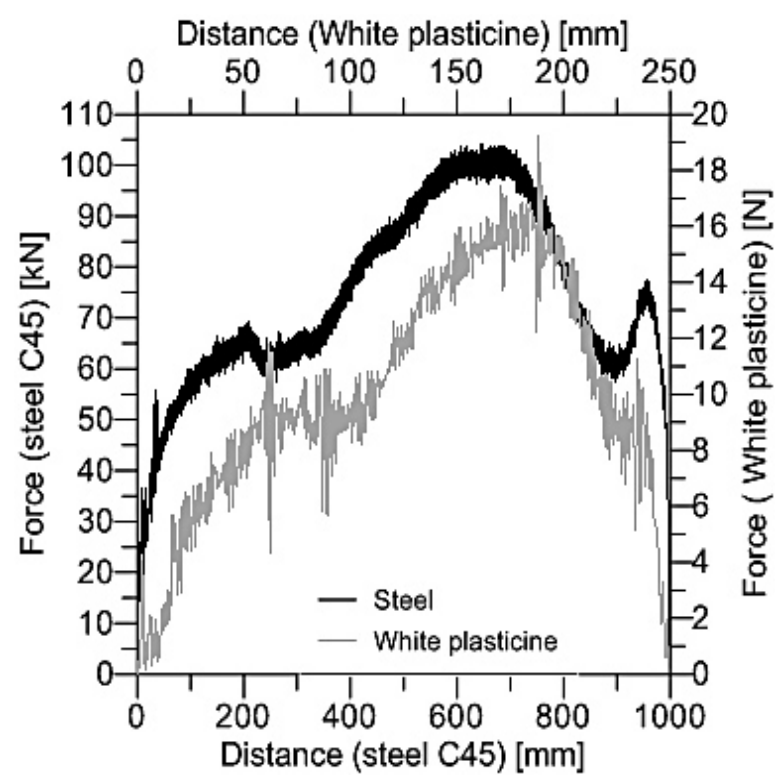

Fig. 10. Comparative diagram of forces for physical modeling and for real process

An attempt was undertaken to estimate the value of the rolling real force, on the basis of results of model research and relation of their similarity. In order to do that the following dependency was used:

$$
P=\lambda \cdot P^{\prime} \cdot s^{2}
$$

where: $\lambda$ - similarity coefficient of model material plasticity [-],

$P^{\prime}$ - forming force from model research $[\mathrm{N}]$, $s-$ tools scale [-].

Values of real force of the analyzed rolling process for particular temperatures of steel forming $\left(1000-1150^{\circ} \mathrm{C}\right)$ were calculated. The assumed scope of temperatures takes into account change of temperature during the cross-wedge rolling process of real forgings. In order to determine main forming force the obtained force values were averaged. For calculations needs similarity coefficients according to table 2 and tools scale "s" equal 4 were assumed. It was also assumed that maximal value of the force during rolling of white plasticine is equal $\mathrm{P}^{\prime}=16 \mathrm{~N}$. Calculations results are given in Table 4.

The force calculated from dependency (4) is equal $112.16 \mathrm{kN}$ while the maximum force obtained during real research reached the value of $116 \mathrm{kN}$. The force determined on the basis of physical modeling is therefore increased by $7 \%$ from the value measured in the real process. In that way the possibility of rolling force estimation in model research conducted with the application of plasticine was confirmed.

Table 3. Dimensions of the obtained forgings

\begin{tabular}{|c|c|c|c|c|c|}
\hline & \multicolumn{2}{|c|}{ Black plasticine } & \multicolumn{2}{c|}{ White plasticine } & Steel C45 \\
\hline Scale & $\begin{array}{c}\text { Model (1:4) } \\
{[\mathrm{mm}]}\end{array}$ & $\begin{array}{c}1: 1 \\
{[\mathrm{~mm}]}\end{array}$ & $\begin{array}{c}\text { Model (1:4) } \\
{[\mathrm{mm}]}\end{array}$ & $\begin{array}{c}1: 1 \\
{[\mathrm{~mm}]}\end{array}$ \\
\hline $\mathrm{d} 1$ & 7.2 & 28.8 & 7.4 & 29.6 & 29.1 \\
\hline $\mathrm{d} 2$ & 8.5 & 34 & 8.6 & 34.4 & 32.8 \\
\hline $\mathrm{d} 3$ & 9.4 & 37.6 & 9.4 & 37.6 & 37.1 \\
\hline $\mathrm{d} 4$ & 14.7 & 58.8 & 14.8 & 59.2 & 59.5 \\
\hline $\mathrm{d} 5$ & 7.7 & 30.8 & 7.8 & 31.2 & 30.7 \\
\hline L1 & 10 & 40 & 10.2 & 40.8 & 41 \\
\hline L2 & 15.1 & 60.4 & 15.4 & 61.6 & 62 \\
\hline L3 & 10 & 40 & 9.9 & 39.6 & 39 \\
\hline L4 & 5.7 & 22.8 & 5.1 & 20.4 & 21 \\
\hline L5 & 37.7 & 150.8 & 37.6 & 150.4 & 148.5 \\
\hline
\end{tabular}


Table 4. Comparison of calculated force values

\begin{tabular}{|c|c|c|c|c|c|}
\hline \multirow{2}{*}{$\mathrm{P}[\mathrm{N}]$} & \multicolumn{5}{|c|}{ TEMPERAATURE OF STEEL T $\left[{ }^{\circ} \mathrm{C}\right]$} \\
\cline { 2 - 6 } & 1150 & 1100 & 1050 & 1000 & $\mathrm{P}_{\mathrm{sr}}$ \\
\hline Plasticine & 84480 & 100838 & 120141 & 143163 & 112155.52 \\
\hline
\end{tabular}

\section{CONCLUSIONS}

The paper presents the progress and results of the model-physical analysis of CWR process of a stepped shaft. Diagrams of the forming forces of a shaft obtained for plastics and steel processed in hot at the temperature of $1150^{\circ} \mathrm{C}$ were presented. The plastic mass (white and black plasticine) was treated at $15^{\circ} \mathrm{C}$. Basing on the collected data and results, it was observed that the white plasticine at $15^{\circ} \mathrm{C}$ better reflects the specifics of the process of the CWR than black plasticine. For this mass better mapping of model forgings shape in comparison with the real process was obtained. It was also observed that white plasticine better mapped the course of force during forging forming. The maximum rolling force counted from the ratio of similarity is $7 \%$ greater than that obtained in real process. During research, it was observed that the sensitivity of plasticine to external factors imposes carrying out the research work under special conditions. Failure to maintain proper precautions may cause burdening results with a significant error, and because of that the necessary procedures for the preparation and storage of the material model are needed.

It was also stated that small forces occurring during forming allow for the usage of simple and low-cost tool materials that can be made of nonmetallic materials.

\section{REFERENCES}

1. Asswmpour A., Razi S. Physical modeling of extrusion process. Journal of Mechanical Ennineering, 4, 2003, 61-69.

2. Balasundar I., Sudhakara M., Raghu T. Equal channel angular pressing die to extrude a variety of materials. Materials and Design, 30, 2009, 1050-1059.

3. Chitkara N.R., Johnson W., Uttley J.R.S. Ball rolling: a literature survey and some experimental results. Proceedings of the Fifteenth International Machine Tool Design and Research Conference, 1975, 497-506.
4. Gontarz A., Łukasik K., Pater Z. Technologia kształtowania i modelowania nowego procesu wytwarzania wkrętów szynowych. Lublin, 2003.

5. Gontarz A., Winiarski G. Numerical and experimental study of producing flanges on hollow parts by extrusion with a movable sleeve. Archives of Metallurgy and Materials, 60, 2015, 1917-1921.

6. Komori K., Mizuno K. Study on plastic deformation in cone type rotary piercing using model piercing mill for modelling clay. Journal of Material Processing Technology, 209, 2009, 4994-5001.

7. Kowalczyk L. Modelowanie fizykalne procesów obróbki plastycznej. Radom ,1995.

8. Mandic V., Stefanovic M., Physical modelling and FEM simulation of the hot bulk forming processes. Journal for Technology of Plasticity, 27, 2002, 41-53.

9. Miresaeidi M., Biglari F.R., Nikbin K., Moazami E., Bagherzadeh S. Optimum Forging Preform Shape Design by Interpolation of Boundary Nodes. Proceedings of the World Congress on Engineering, 2, 2009.

10. Pater Z. Walcowanie poprzeczno-klinowe. Lublin, 2009

11. Pater Z., Samołyk G. Podstawy technologii obróbki plastycznej metali. Lublin, 2013.

12. Pertence A.E.M., Cetlin P.R. Analysis of a new model material for the physical simulation of metal forming. Journal of Materials Processing Technology, 84,1998, 261-267.

13. Segawa A., Kawanami T., Rolling-deformation characteristics of clad materials determined by model experiment and numerical simulation: experimental rolling tests using plasticine. Journal of Material Processing Technology, 47, 1995, 375-384.

14. Shih C., Hung C. Experimental and numerical analyses on three-roll planetary rolling process. Journal of Material Processing Technology, 142, 2003, 702-709.

15. Shih C., Hung C., Hsu R. The finite element analysis of planetary rolling process. Journal of Material Processing Technology, 113, 2001, 115-123.

16. Sofuoglu H., Rasty J. Flow behavior of Plasticine used in physical modeling of metal forming processes. Tribology International, 33, 2000, 523-529.

17. Świątkowski K. Analiza badań modelowych z 
użyciem materiałów modelowych z użyciem materiałów woskowych. Obróbka Plastyczna Metali, 5, 1994, 5-14.

18. Świątkowski K. Własności mechaniczne woskowych materiałów modelowych. Obróbka Plastyczna, 5, 1994, 15-21.

19. Vazquez V., Altan T. New Concepts in die design - physical and computer modeling applications. Journal of Materials Processing Technology,
98, 2000, 212-223.

20. Wong S.F., Hodgson P.D., Chong C.J., Thomson P.F. Physical modelling with application to metal working especially to hot rolling. Journal of Material Processing Technology, 62, 1996, 260-274.

21. M.Zhan, Y.Liu, H.Yang, Physical modelling of the forging of a blade with a zdamper platform using plasticine, Journal of Material Processing Technology, 117, 2001, 62-65. 